\title{
The high burden of infant deaths in rural Burkina Faso: a prospective community-based cohort study
}

\author{
Abdoulaye Hama Diallo ${ }^{1,2^{*}}$, Nicolas Meda ${ }^{1}$, Halvor Sommerfelt ${ }^{2,3}$, Germain S Traore ${ }^{4}$, Simon Cousens ${ }^{5}$ \\ and Thorkild Tylleskar ${ }^{2}$ for the PROMISE-EBF study group
}

\begin{abstract}
Background: Infant mortality rates (IMR) remain high in many sub-Saharan African countries, especially in rural settings where access to health services may be limited. Studies in such communities can provide relevant data on the burden of and risk factors for infant death. We measured IMR and explored risk factors for infant death in a cohort of children born in Banfora Health District, a rural area in South-West Burkina Faso.

Methods: A prospective community-based cohort study was nested within the PROMISE-EBF trial (NCT00397150) in 24 villages of the study area. Maternal and infant baseline characteristics were collected at recruitment and after birth, respectively. Home visits were conducted at weeks 3, 6, 12, 24 and 52 after birth. Descriptive statistics were calculated using robust standard errors to account for cluster sampling. Cox multivariable regression was used to investigate potential risk factors for infant death.

Results: Among the 866 live born children included in the study there were 98 infant deaths, yielding an IMR of 113 per 1000 live births (95\% Cl: 89-143). Over 75\% of infant deaths had occurred by 6 months of age and the post neonatal infant mortality rate was 67 per 1000 live births (95\% Cl: 51-88). Infections (35\%) and preterm births complications (23\%) were the most common probable causes of death by 6 months. Multivariable analyses identified maternal history of child death, polygyny, twin births and poor anthropometric z-scores at week-3 as factors associated with increased risk of infant death.

Conclusions: We observed a very high IMR in a rural area of Burkina Faso, a country where $75 \%$ of the population lives in rural settings. Community-based health interventions targeting mothers and children at high risk are urgently needed to reduce the high burden of infant deaths in these areas.
\end{abstract}

Keywords: Infant mortality, Risk factors, Rural areas, Burkina Faso

\section{Background}

Millennium Development Goal 4 (MDG-4) calls for a two-thirds reduction in the under-five year mortality rates (U5MR) between 1990 and 2015 [1]. An important contributor to under-five mortality is infant mortality, which in 2010 represented $70 \%$ of all child deaths, i.e. 5.4 million deaths of an estimated global burden of approximately 7.7 million child deaths under-five years of

\footnotetext{
* Correspondence: hamadial@yahoo.fr

${ }^{1}$ Centre MURAZ Research Institute, Ministry of Health/Burkina Faso, PO Box 390, Bobo-Dioulasso, Burkina Faso

${ }^{2}$ Centre for International Health $(\mathrm{ClH})$, University of Bergen, PO Box 7804N-5020, Bergen, Norway

Full list of author information is available at the end of the article
}

age [2]. An important component of infant deaths is neonatal deaths.

The worldwide infant mortality rate (IMR) was estimated by the United Nations Children Fund (UNICEF) to be 42 per 1000 live births in 2009, with Sub-Saharan Africa the region with the highest rate (81 per 1000 live births) [3]. However, recent publications have suggested a substantial reduction in post-neonatal mortality rates over the last twenty years (1990-2009) with an annual average reduction globally of $2.2 \%$ [2,4-6]. But, the rate of IMR reduction in Sub-Saharan Africa has been lower than in Asia [3,7]. In addition, there are substantial regional and within-country variations in IMRs and their 
reduction over time [2,3,6]. Within Africa, Central and West Africa are the two regions with highest IMRs, as high as 92 per 1000 live births, 10 points above the SubSaharan Africa average [8].

An important observation on recently published estimates on child deaths including infant mortality is the shifting figures of the global estimates of child mortality, owing partly to the lack of reliable statistics in many countries where the burden is the highest, and also to changes in statistical methods used for the estimates [2-7]. Several reports have called for the collection of high quality data in low-income countries, especially in rural areas of Africa where the decrease in child mortality has been slow [4-6,9,10].

With just a few years to go until the MDG-4 deadline, several reports suggest that very few Sub-Saharan African countries are likely to meet this goal by 2015 $[4,6]$. It is therefore important to monitor the MDG-4 progress in the countries with the highest IMRs in order to provide more reliable statistics of this outcome and also to guide policy makers for relevant and contextualized local health programs.

Monitoring child mortality in a country like Burkina Faso (West Africa) where over $75 \%$ of the population lives in rural settings [11] will benefit from studies that are conducted in rural communities, also those with poor access to health care facilities, and when possible using a prospective study design.

The present study seeks to contribute to this global effort of quality data production and reports on the findings from a community-based cohort study that sought to measure IMR in a rural area in Burkina Faso and explore possible risk factors for infant death.

\section{Methods}

\section{Study area}

The study took place in Banfora Health District, in the south-west of Burkina Faso close to the border with Cote d"Ivoire. The district covers an area of $6,300 \mathrm{~km}^{2 \text {, }}$ and had an estimated population of 282,000 in 2010 with three major ethnic groups, the Gouin, the Karoboro and the Dioula [11]. The area experiences an annual rainfall of 950 to $1250 \mathrm{~mm}$ during a 6-month rainy season (May-Oct). Farming and animal husbandry are the main activities in the rural areas while the town of Banfora with a population of 75,000 is a flourishing trading centre [11]. The study was conducted in three subcounties, Banfora, Soubakénédougou and Sidéradougou (Figure 1).

In 2006, the district health system consisted of 60 primary health facilities and one regional hospital in the town of Banfora. The ratios of health personnel to population in 2010 were estimated to be approximately 1:5300 for nurses, 1:5200 for midwives, and 1:40000 for physicians [12].
Based on official reports for the study area from the Ministry of Health in Burkina Faso, over 94\% of pregnant women attended antenatal care (ANC), 77\% were reported to deliver in a health facility and $66 \%$ of children aged 12-23 months were reported to have received the full set of EPI vaccines in 2010 [13]. HIV-prevalence is low in the rural areas of Banfora region and was estimated to be of $0.6 \%$ among the 15-49 years-old in 2010 [13]. The 2006-national census in Burkina Faso reported Banfora to have an IMR of 101 and a U5MR of 165 per 1000 live births [11].

\section{Study design}

A cohort study was nested within the PROMISE-EBF trial (www.clinicaltrials.gov NCT00397150), a community-based, cluster-randomized trial to promote exclusive breastfeeding (EBF) through individual peer-counselling, which was implemented in 24 villages of Banfora Health District as reported elsewhere [14,15]. Children born to all pregnant women enrolled in both arms of the main PROMISE-EBF trial formed a prospective cohort that was followed until 12 months of age.

\section{Sample size}

The PROMISE-EBF trial sample size was calculated using prevalence of EBF and diarrhea at 12 weeks of child age as primary outcomes [14,15]. No sample size estimation was done for infant deaths. However, posthoc analyses showed that the sample of 866 newborns enrolled would enable us to estimate the IMR with a precision of $\pm 2 \%$ based on estimates from the 2006national census in Burkina Faso [11] and a confidence level of $95 \%$.

\section{Recruitment and follow-up of study participants}

The details of participants' enrolment and follow-up for the first 6 months are reported elsewhere $[14,16]$. In summary, pregnant women were identified in each study village by female "recruiters" over a one year period (June 2006 to May 2007) through weekly household visits. In 23 villages with a mean population of 1330 , a random sample of up to 4 pregnant women per village was selected monthly. In the $24^{\text {th }}$ village (Siniéna) with a population of nearly 5000, we sampled 8 women per month instead of 4 . Women were recruited into the EBF-trial if they met the study inclusion criteria which were as follows: pregnancy of 7 months or more, intention to remain in the village for the next 12 months, plan to breastfeed the child, absence of any severe maternal disease or mental handicap which could prevent either breastfeeding or cooperation and provision of individually written and informed consent.

While the main EBF-trial included only singleton live births and planned a follow-up for 6 months, we report here on all live born children of enrolled mothers, 


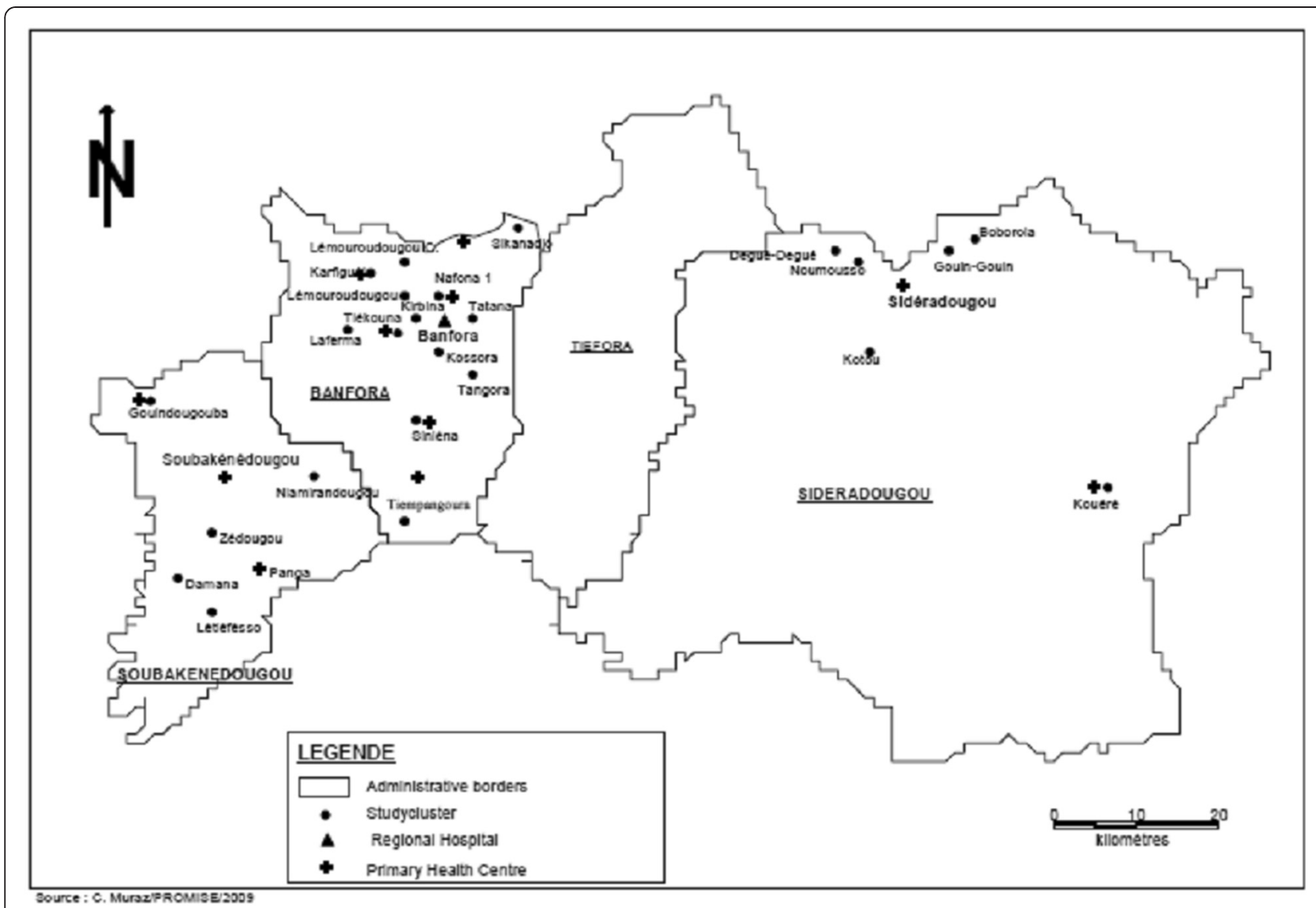

Figure 1 Overview of the study area.

including those who had multiple births. Children were followed-up by trained data collectors, irrespective of trial arm until they were 12 months or older. Data collection visits were scheduled at recruitment and after birth at day 7 and at weeks 3, 6, 12, 24 ( \pm 7 days for each visit) and at 12 months. Mothers who were not at home for a scheduled home visit were revisited by data collectors three times before the visit was considered as missed. Data collection lasted from March 2006 to November 2008.

Maternal baseline data (age, parity, medical history, household assets, etc.) were recorded at enrolment. Pregnancy outcomes and newborn baseline data were collected during the day-7 visit or at the earliest completed visit after birth. Newborn birth weight was recorded from the child health card when available. From week-3, we recorded information on the child's feeding pattern and growth. Deaths at any time after birth were recorded. Infant weight and height were measured at each home visit using Seca ${ }^{\circledR} 872$ scales and a Seca ${ }^{\circledR} 210$ infantometer (www.seca.com), respectively. Weight was recorded to the nearest $0.10 \mathrm{~kg}$ and height was measured to the nearest $0.5 \mathrm{~cm}$. All interviews were conducted in the mother's local language to improve comprehension and cooperation.

A standard verbal autopsy (VA) questionnaire [17] was used to capture information on the circumstances surrounding infant deaths and was filled within 4-6 weeks. However, narrative items describing the causes of death were completed only for infants who died before 6 months of age and so cause of death was only assessed for deaths before 6 months of age. Two independent physicians reviewed the VAs to assign probable causes of death using a hierarchical grouping adapted from the Child Health Epidemiology Reference Group Classification [18] and ICD-10. Deaths during the neonatal period were classified into the following sequential cause groups: congenital defects, tetanus, trauma/surgical, preterm birth complications, birth asphyxia, sepsis/ pneumonia, diarrhoea/gastroenteritis, other/unknown. Postneonatal deaths were classified into the following causes: diarrhoea/gastroenteritis, pertussis, measles, injury/surgical, meningitis, pneumonia/acute respiratory tract infection, malaria, malnutrition, other/unknown. Multiple causes were allowed, although only the primary cause of death is reported here. The opinion of a senior 
paediatrician was sought in cases of disagreement between the two physicians.

Data collection was done using handheld computers (PDAs) with the Epihandy software (www.openXdata. org) for visits up to 6 months, and with paper forms for the 12 month visit.

\section{Outcomes and exposures definitions}

We used the WHO's standard definitions of neonatal (i.e. death of a live born newborn within 28 days), postneonatal (i.e. death of an infant between 1-12 months) and infant death (i.e. the death of any live born infant before 12 months of age). The main exposures included in analyses were maternal baseline characteristics (age, parity, education, socioeconomic status, use of health services and medical history) and newborn characteristics (season of birth, sex, twinship and anthropometry). Children with birth weight $<2500$ g were considered as low birth weight. Anthropometric status was assessed using WHO's standards (http://www.who.int/childgrowth/en/). Children were classified as wasted, stunted or underweight if their relevant $\mathrm{z}$-score was below -2 . A child with any $\mathrm{z}$-score $<-2$ at 3 weeks of age was defined as having a "low anthropometric score".

\section{Data entry and analysis}

Data collected on paper questionnaires were entered by two independent clerks using Epidata 3.1 (www.epidata. $\mathrm{dk}$ ), cleaned and merged with the cleaned datasets from the electronic questionnaires. Data were analyzed with STATA/SE 11.0 (Statacorp, College Station, Texas).

Summary statistics of continuous and discrete variables of mothers and infants were produced. The 95\% confidence intervals $(\mathrm{CI})$ of proportions were calculated using robust standard errors to account for the cluster sampling of the PROMISE-EBF trial.

Risk of death by one year of age (commonly known as IMR) was calculated as the proportion of infant deaths per 1000 live births and a 95\% CI calculated using a robust standard error.

Mortality rates were estimated using survival analysis and are reported per 1000 person-years of observation (PYO). A Kaplan-Meier plot was produced to show cumulative risk of death until 12 months. Between-cluster variation in mortality rates was assessed using a likelihood ratio test (LR test) with a random-effects Cox regression model.

Potential risk factors for infant deaths were screened through univariable Cox regression models for three age ranges (0-6 months, 1-12 months and 0-12 months). These analyses took account of possible clustering (fitting Cox Gamma shared frailty models in STATA/SE $11.0)$ and only variables with a $\mathrm{p}<0.25$ in Wald-statistic tests were retained for further exploration. We explored interactions between polygyny and several maternal baseline variables including distance to nearest health facility, education, parity, ANC visits, and health facility delivery. We also looked at interactions between health facility delivery and maternal education or parity. Based on Mosley and Chen's model [19] for risk factors assessment in child mortality, we conducted multivariable Cox regression models adjusting for distance to nearest health facility, maternal history of child death, newborn's season of birth and sex considered as potential confounders. Covariates that remained associated with infant death risk $(\mathrm{p}<0.05)$ in the adjusted models and that met major criteria for causal inference [20] were considered as risk factors.

\section{Ethical and administrative clearances}

The study was approved by the Institutional Review Board of Centre MURAZ in Burkina Faso (No13/2005/CE-CM) and by the Western Regional Committee for Medical and Health Research Ethics in Norway (Sak No05/8197). Administrative clearances were sought from the national and regional health authorities of Burkina Faso. All study participants were requested to provide individually written and informed consent prior to enrolment. All mothers and infants included in the study were offered free care and medication in local health facilities for the duration of the study, for illnesses related to lactational problems (mastitis, breast abscess) and infections (pneumonia, diarrhoea and malaria).

\section{Results}

\section{Baseline data}

Over a one-year period, 1162 pregnant women were identified, 895 of whom were enrolled in the study (Figure 2). There were a total of 866 live births including 20 pairs of twins. The vital status of all infants was known at 12 months of age, although for 15 children (1.7\%), data were collected from a close relative as they had relocated out of the study clusters.

There was an average of 36 live births recruited per village, with a range of $16-86$. One village, Siniéna had a population of 5,000 and a higher number of births recruited $(\mathrm{N}=86)$. Only six villages $(25 \%)$ had a local health facility and $31 \%$ of infants were born in these villages. The proportion of twins births was particularly high $(22 \%)$ in one village (Nafona1).

The average maternal age at enrolment was 26.4 years $(\mathrm{SD}=6.5)$ and the median parity $3(\mathrm{IQR}=2-4)$. High proportions of mothers were multiparae $(84 \%)$ and had no formal education (80\%). Almost half (48\%) lived in polygynous households. About $60 \%$ of multiparous women had experienced a previous child death. Only $18 \%$ of the mothers had attended $\geq 2$ antenatal care visits (ANC) by the time of recruitment and the proportion of health- 


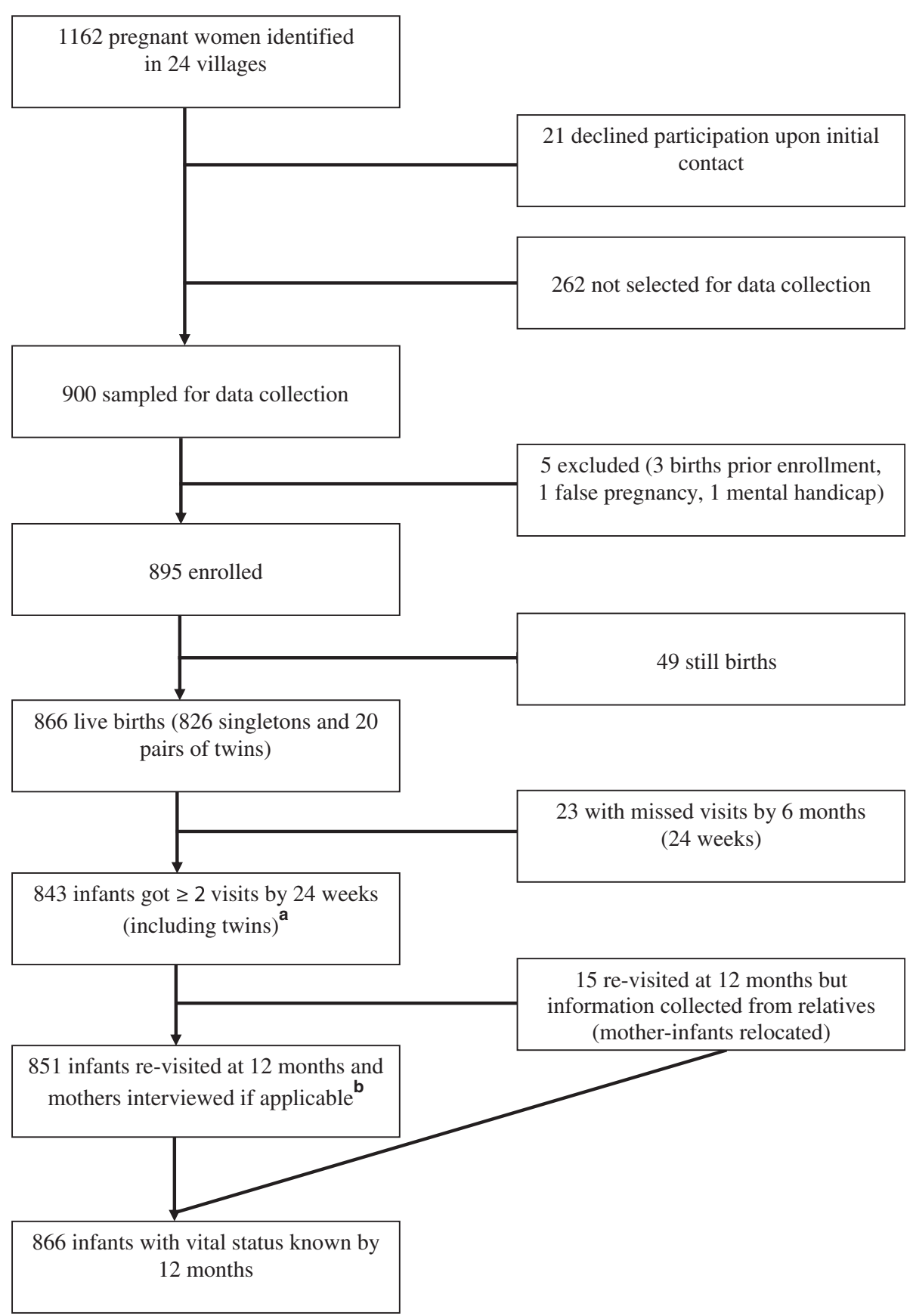

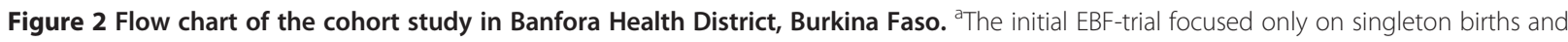
was scheduled at weeks 3, 6,12 and 24. The cohort follow-up included twins and added further visits at day 7 and 12 months after birth. ${ }^{\mathbf{b}}$ Mothers whose children had died and were initially interviewed (verbal autopsy) were visited for formal greetings but not re-interviewed.

facility deliveries was only $38 \%$. The number of ANCvisits and the proportion of facility-deliveries varied inversely with parity (chi ${ }^{2}$ tests for trend, $\mathrm{p}<0.001$ in both cases). We found no evidence that maternal education or an index of household assets was associated with the use of health services during pregnancy $(\mathrm{p}=0.41$ and $\mathrm{p}=0.48$, respectively $)$ or at delivery $(\mathrm{p}=0.16$ and $\mathrm{p}=0.42$, respectively).
Only 295 newborns, all born in health facilities, had a birth weight recorded on the child health card. Among the 723 children with weight and length measured at week-3, all three median z-scores were negative (Table 1), indicating poor anthropometric status among infants of this population. Overall, 212 infants (29\%) at week-3 visit had a low $\mathrm{z}$-score (<-2 SD) of whom $21(3 \%)$ were stunted, 71 (10\%) were wasted, 25 (3\%) were underweight, 
Table 1 Maternal and infant baseline, number of infant deaths and infant mortality rates in a cohort of 866 live births in Banfora Health District, Burkina Faso

\begin{tabular}{|c|c|c|c|c|}
\hline & Mothers $(n=846)$ & Live births $(n=866)$ & Infant deaths & Infant $r$ \\
\hline & $N(\%)$ & $N(\%)$ & $(N=98)$ & \\
\hline \multicolumn{5}{|l|}{ Categorical variables } \\
\hline \multicolumn{5}{|l|}{ Area of residence } \\
\hline Banfora & $418(49)$ & $429(50)$ & 56 & 130.5 \\
\hline Soubakénédougou & $208(25)$ & $212(24)$ & 18 & 85.0 \\
\hline Sidéradougou & $220(26)$ & $225(26)$ & 24 & 106.7 \\
\hline \multicolumn{5}{|c|}{ Distance to nearest health facility } \\
\hline$\leq 5 \mathrm{~km}$ & $406(48)$ & $419(48)$ & 55 & 131.3 \\
\hline$>5 \mathrm{~km}$ & $440(52)$ & $447(52)$ & 43 & 96.2 \\
\hline \multicolumn{5}{|l|}{ Maternal age } \\
\hline$<20$ & $132(16)$ & $133(15)$ & 17 & 127.8 \\
\hline 20-35 & $626(74)$ & $644(75)$ & 75 & 116.5 \\
\hline$>35$ & $88(10)$ & $89(10)$ & 6 & 67.4 \\
\hline \multicolumn{5}{|l|}{ Parity } \\
\hline 0 & $138(16)$ & $139(16)$ & 19 & 136.7 \\
\hline 1 & $137(16)$ & $141(16)$ & 17 & 120.6 \\
\hline $2-4$ & $393(47)$ & $406(47)$ & 43 & 105.9 \\
\hline $5+$ & $178(21)$ & $180(21)$ & 19 & 105.6 \\
\hline \multicolumn{5}{|l|}{ Polygynous household } \\
\hline Yes & $409(48)$ & $420(48)$ & 61 & 145.2 \\
\hline No & $437(52)$ & $446(52)$ & 37 & 83.0 \\
\hline \multicolumn{5}{|l|}{ Maternal education } \\
\hline None & $678(80)$ & $694(80)$ & 78 & 112.4 \\
\hline Literacy/primary school & $116(14)$ & $120(14)$ & 17 & 141.7 \\
\hline Secondary school & $52(06)$ & $52(06)$ & 3 & 57.7 \\
\hline \multicolumn{5}{|l|}{ Socio-economic status } \\
\hline \multicolumn{5}{|c|}{ (based on household assets) $^{a}$} \\
\hline Quintile 1 (most poor) & $182(22)$ & $184(21)$ & 17 & 92.4 \\
\hline Quintile 2 & $156(18)$ & 163 (19) & 26 & 159.5 \\
\hline Quintile 3 & $178(21)$ & $178(21)$ & 21 & 118.0 \\
\hline Quintile 4 & $166(20)$ & $174(20)$ & 14 & 80.5 \\
\hline Quintile 5 (least poor) & $164(19)$ & 167 (19) & 20 & 119.8 \\
\hline \multicolumn{5}{|l|}{ Previous child death $^{\mathrm{b}}$} \\
\hline Yes & $419(59)$ & $429(59)$ & 54 & 125.9 \\
\hline No & $289(41)$ & $298(41)$ & 25 & 83.9 \\
\hline \multicolumn{5}{|l|}{ Antenatal care visits } \\
\hline 0 & $237(28)$ & $240(28)$ & 25 & 104.2 \\
\hline $1-2$ & $455(54)$ & $466(54)$ & 58 & 124.5 \\
\hline$>2$ & $154(18)$ & $160(18)$ & 15 & 93.8 \\
\hline \multicolumn{5}{|c|}{ Mother sleeps under bednet } \\
\hline Yes & $324(38)$ & $332(38)$ & 32 & 96.4 \\
\hline No & $522(62)$ & $534(62)$ & 66 & 123.6 \\
\hline
\end{tabular}


Table 1 Maternal and infant baseline, number of infant deaths and infant mortality rates in a cohort of 866 live births in Banfora Health District, Burkina Faso (Continued)

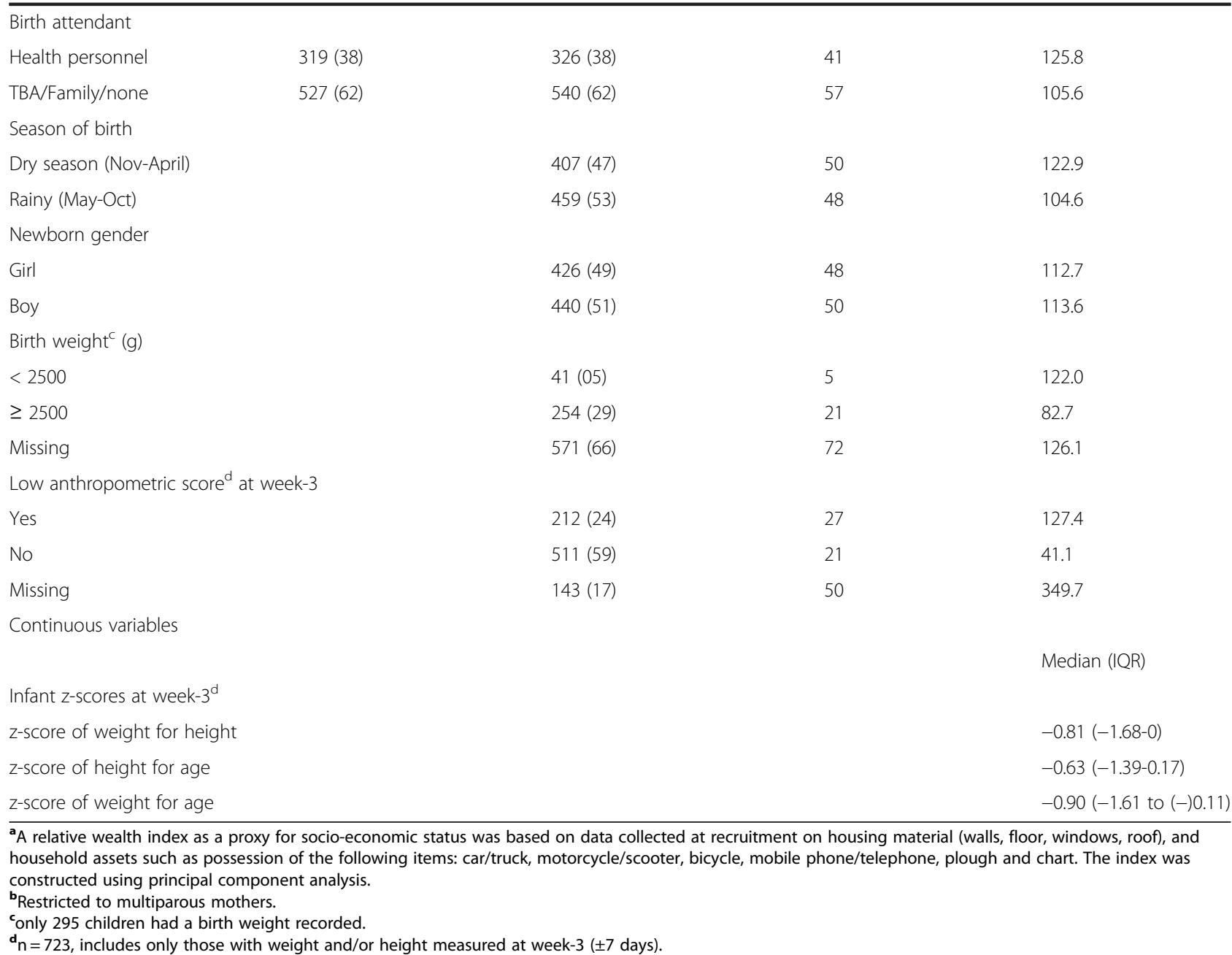

and 95 (13\%) had two or three of these outcomes together.

\section{Infant mortality}

A total of 98 infant deaths were recorded, yielding an IMR of 113 per 1000 live births (95\% CI: 89-143, Figure 3). Of these, 58 deaths (59\%) occurred after 28 days, yielding a post-neonatal infant mortality rate of 67 per 1000 live births (95\% CI: 51-88). Overall, neonatal deaths $(\mathrm{N}=40)$ and infant deaths by 6 months of age $(\mathrm{N}=75)$ represented $41 \%$ and $76 \%$ of all infant deaths, respectively. The distributions of child deaths by maternal and infant baseline characteristics are presented in Table 1 . Infant deaths occurred in 23 out of the 24 villages and in 13 of them (54\%), IMR exceeded 100 per 1000 live births (Table 2). Two villages, Karfiguéla and Nafona1, had very high IMRs of 286 and 250 per 1000, respectively; both had a health facility (Table 2). However, we found no evidence that the between village variation in observed IMR was higher than might be expected due to chance (LR test, $\mathrm{p}=0.32$ ).
Mortality rates (MRs) per 1000 PYOs were very high during the neonatal period ( $\mathrm{MR}=610,95 \% \mathrm{CI}$ : 448-832) and fell rapidly after 4 weeks $(\mathrm{MR}=79,95 \mathrm{CI} \% \mathrm{CI}$ : $61-$ 102). The average MR from birth to 12 months of age was of 123 (95\% CI: 101-150) per 1000 PYOs.

\section{Probable causes of deaths during the first half of infancy} The distribution of the probable causes of death by 6 months of age $(\mathrm{N}=75)$ is presented in Table 3. During the neonatal period, preterm birth complications (42\%) and infections (17\%) were the main causes of death while infections (54\%) were the major cause of infant deaths in the postneonatal period, dominated by acute respiratory infections (7 cases), malaria (7 cases), meningitis (3 cases) and gastroenteritis ( 2 cases). The causes of death were unknown for 26 infants (35\%), mainly due to missing information from mothers (Table 3).

A total of 67 (89\%) deaths by 6 months of age occurred at home, 7 deaths (9\%) occurred in a local health facility, and one death occurred in a local healer's home. 


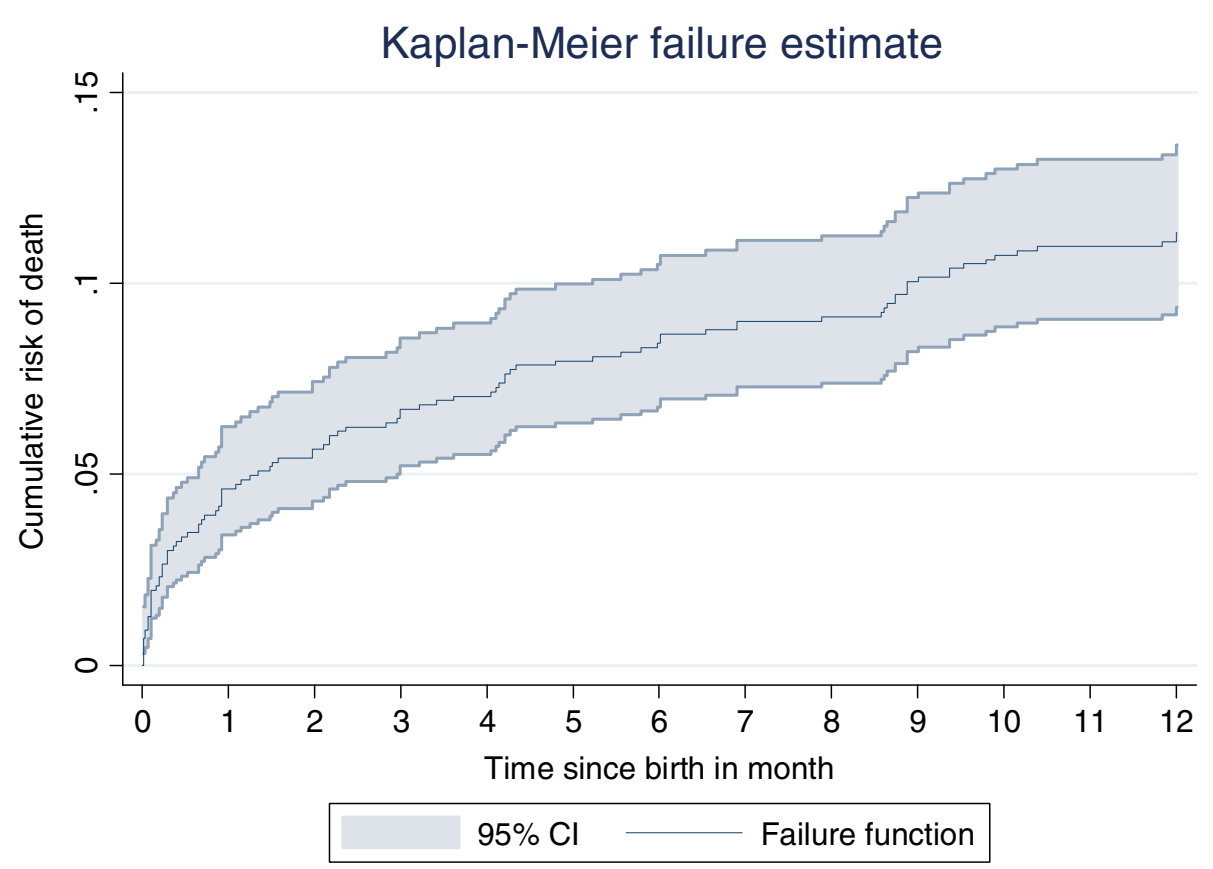

Figure 3 Cumulative risk of infant death with $95 \% \mathrm{Cl}$ in a survival analysis of a cohort of 866 live births in Banfora Health District, Burkina Faso.

Of the children who died before 6 months of age, only $16(21 \%)$ were taken to a health facility prior to death. For 10 of these children (63\%), the treatment recorded on the child health card was an antimalarial drug (chloroquine, amodiaquine, or quinine).

\section{Risk factors for infant death}

During the first half of infancy (0-6 months), polygyny, twinship and low anthropometric z-scores at week-3 were factors strongly associated with increased rate of death in univariable Cox regressions (Table 4). Twins had over 8-fold increased rate of death at this age compared to singletons and children with low anthropometric z-score had 4-times higher rate of death compared to their peers with a $z$-score $\geq-2$. There was some weak evidence that a residence closer to health facility, maternal history of child death, being a boy and birth during the dry season were associated with increased rates of infant death (Table 4). After controlling for potential confounders, children from polygynous households, those born to mothers with a previous child death, boys and twin births appeared to experience higher mortality rates between 0 and 6 months of age (Table 5).

In the postneonatal period, there were 3 variables associated with increased rate of death in univariable analyses (Table 4): infants of mothers not sleeping under bednet $(\mathrm{HR}=1.6,95 \% \mathrm{CI}: 1.0-2.8)$, twin births $(\mathrm{HR}=6.7$, 95\% CI:3.5-12.7) and children with low anthropometric z-scores at week-3 ( $\mathrm{HR}=3.2,95 \% \mathrm{CI}: 1.8-5.7)$. There was weak evidence that infants born in polygynous households and those whose mothers had a history of child death were at higher risk of postneonatal death. The adjusted models showed a doubling of the rate of death for children born in polygynous households $(\mathrm{HR}=2.0$, 95\% CI: 1.1-3.6) and over 3-times higher rate of death for children with poor anthropometric status at 3 weeks of age (Table 5). There was a $80 \%$ (95\% CI: -10 to $240 \%$ ) higher rate of postneonatal death for infants whose mothers were not sleeping under a bednet.

For the entire period of infancy, there were 3 factors strongly associated with increased rate of infant death (Table 5): maternal history of child death ( $\mathrm{HR}=1.6,95 \%$ CI: 1.0-2.6), birth in a polygynous household $(\mathrm{HR}=2.4$, 95\% CI: 1.4-4.0) and twin births (HR $=8.4$, 95\% CI: 4.615.3). We found no further evidence of an increased rate of death among children living closer to a health facility in the multivariable models (Table 5). The observed higher rate of death among children living closer to a health facility in the crude analysis (Table 4) was no longer present when the two clusters with the highest IMRs and both with a local facility were excluded ( $\mathrm{HR}=0.9,95 \% \mathrm{CI}$ : 0.61.3) or when the cut-off point was set to $10 \mathrm{~km}(\mathrm{HR}=0.81$, 95\% CI: 0.5-1.3). We did not find any evidence in multivariable analyses that a birth in the dry season or being a boy was associated with a significantly increased rate of infant death in this cohort (Table 5). 
Table 2 Distribution of facilities, number of live births, infant deaths and infant mortality rates at 6 and 12 months of child age in 24 villages of Banfora Health District (Burkina Faso)

\begin{tabular}{|c|c|c|c|c|c|c|c|c|}
\hline No & Village & $\begin{array}{l}\text { Health } \\
\text { facility } \\
\text { exists }\end{array}$ & $\begin{array}{c}\text { Distance } \\
\text { to health } \\
\text { facility } \\
\text { (km) }\end{array}$ & $\begin{array}{c}\text { Number } \\
\text { of live } \\
\text { births }\end{array}$ & $\begin{array}{c}\text { Twin } \\
\text { births }\end{array}$ & $\begin{array}{c}\text { Number } \\
\text { of infant } \\
\text { deaths }\end{array}$ & $\frac{\text { HIMR }^{\mathrm{a}}}{\text { Per } 1000}$ & $\frac{\mathrm{IMR}^{\mathrm{b}}}{\text { Per } 1000}$ \\
\hline 1 & Létiéfesso & No & 12 & 42 & 0 & 0 & 0 & 0 \\
\hline 2 & Tangora & No & 10 & 41 & 2 & 1 & 0 & 24 \\
\hline 3 & Lémouroudougou cité & No & 15 & 16 & 0 & 1 & 62 & 62 \\
\hline 4 & Gouindougouba & Yes & 0 & 44 & 2 & 3 & 45 & 68 \\
\hline 5 & Lémouroudougou village & No & 10 & 29 & 2 & 2 & 34 & 69 \\
\hline 6 & Kirbina & No & 5 & 28 & 0 & 2 & 71 & 71 \\
\hline 7 & Boborola & No & 8 & 41 & 2 & 3 & 49 & 73 \\
\hline 8 & Gouin-Gouin & No & 5 & 39 & 0 & 3 & 51 & 77 \\
\hline 9 & Kossara & No & 4 & 22 & 0 & 2 & 91 & 91 \\
\hline 10 & Tatana & No & 3 & 30 & 0 & 3 & 100 & 100 \\
\hline 11 & Kouéré & Yes & 0 & 50 & 6 & 5 & 80 & 100 \\
\hline 12 & Niamirandougou & No & 8 & 39 & 2 & 4 & 103 & 102 \\
\hline 13 & Tiékouna & Yes & 0 & 28 & 0 & 3 & 71 & 107 \\
\hline 14 & Noumousso & No & 4 & 28 & 2 & 3 & 107 & 107 \\
\hline 15 & Sikanadjo & No & 19 & 18 & 0 & 2 & 111 & 111 \\
\hline 16 & Dêgue-Dêgue & No & 14 & 35 & 0 & 4 & 86 & 114 \\
\hline 17 & Damana & No & 16 & 42 & 0 & 5 & 48 & 119 \\
\hline 18 & Laferma & No & 7 & 32 & 2 & 4 & 125 & 125 \\
\hline 19 & Zédougou & No & 11 & 45 & 4 & 6 & 111 & 133 \\
\hline 20 & Tiempangora & No & 16 & 35 & 0 & 5 & 57 & 143 \\
\hline 21 & Siniéna & Yes & 0 & 86 & 6 & 14 & 93 & 163 \\
\hline 22 & Kotou & No & 7 & 32 & 0 & 6 & 156 & 187 \\
\hline 23 & Nafona1 & Yes & 0 & 36 & 8 & 9 & 250 & 250 \\
\hline 24 & Karfiguélac & Yes & 0 & 28 & 2 & 8 & 250 & 286 \\
\hline Mean (SD) ${ }^{\mathbf{d}}$ & & - & - & $36(13)$ & - & $4(3)$ & $90(61)$ & $112(63)$ \\
\hline
\end{tabular}

${ }^{a} 1^{\text {st }}$ half of infancy mortality rate (HIMR, i.e. from 0 to 6 months) is expressed per 1000 live births.

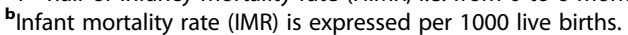

'Clusters are ranked by increasing order of IMRs, Nafona1 and Karfiguéla located in Banfora subcounty and both with a health facility, had the highest IMRs in this cohort.

${ }^{\mathbf{d}}$ Mean (SD) were obtained from cluster-level summaries of the data by village.

\section{Discussion}

In this community-based prospective cohort study, the IMR was very high. Infections and preterm birth complications were the main probable causes of infant deaths up to 6 months of age. Overall, 2 maternal variables (history of previous child death, polygynous status) and 2 infant characteristics (twin births, poor anthropometric status at 3 weeks of age) were identified as risk factors for infant death.

\section{Estimates of postneonatal and infant mortality rates}

Our estimates of postneonatal mortality rate and IMR are consistent with recent publications on child mortality for Burkina Faso [3,11]. However, these results are almost twice as high as the estimates provided in a recently published provisional report of the 2010-DHS in Burkina Faso, where postneonatal mortality rate and IMR were estimated to 37 and 65 per 1000 live births, respectively [13]. It is important to remember that the estimates provided in DHS are nation-wide averages and could therefore mask within-country variations in the burden of infant deaths. Another limitation of DHS and surveys in general, is the likelihood of recall bias, especially in populations where literacy is very low, such as in Burkina Faso.

We found few recent prospective cohort data on infant mortality in Burkina Faso. In fact, only two communitybased studies one conducted in the Nouna's DSS (North-western part of Burkina) in 2003, and the second in the Oubritenga's DSS (Central part of the country) in 
Table 3 Distribution of the probable causes of infant deaths from 0 to 6 months among 75 children in Banfora Health District, Burkina Faso

\begin{tabular}{|c|c|c|}
\hline \multirow[t]{2}{*}{$\begin{array}{l}\text { Probable causes infant deaths } \\
\text { (0-6 months) }\end{array}$} & \multirow{2}{*}{$\begin{array}{l}\begin{array}{l}\text { Neonatal } \\
\text { period }\end{array} \\
\text { Cases N (\%) }\end{array}$} & \multirow{2}{*}{$\begin{array}{l}\text { Postneonata } \\
\text { period } \\
\text { Cases N (\%) }\end{array}$} \\
\hline & & \\
\hline Infections & $7(17)$ & $19(54)$ \\
\hline $\begin{array}{l}\text { - Acute respiratory infections } \\
\text { (ARI) }\end{array}$ & 3 & 7 \\
\hline - Malaria & 0 & 7 \\
\hline - Meningitis & 0 & 3 \\
\hline - Gastroenteritis & 1 & 2 \\
\hline - Sepsis & 2 & 0 \\
\hline - Fever of unknown aetiology & 1 & 0 \\
\hline Preterm birth complications & $17(42)$ & 0 \\
\hline $\begin{array}{l}\text { Acute intestinal occlusion } \\
\text { syndrome }\end{array}$ & $2(05)$ & 0 \\
\hline Severe haemorrhages & $1(03)$ & $1(03)$ \\
\hline Birth asphyxia & $1(03)$ & 0 \\
\hline Severe malnutrition & $0(0)$ & $1(03)$ \\
\hline Unknown ${ }^{\mathbf{a}}$ & $12(30)$ & $14(40)$ \\
\hline Total & 40 & 35 \\
\hline
\end{tabular}

${ }^{a}$ Either the verbal autopsy could not allow any conclusion from the medical reviewers ( 5 cases) or the detailed history of death was missing (21 cases).

2000 reported estimates of IMRs lower than ours, at 67.8 and 56.7 per 1000 , respectively [21,22]. The context of these two studies may explain the observed difference as several health interventions were going on both sites [21,23-29].

One important reason for the observed high burden of infant death in a rural area of Burkina Faso is the patchy and weak health system, as suggested by other studies $[30,31]$. Coverage and utilization of health facilities were low in Banfora and concerns about the quality of care have been raised $[12,16]$. In this study, only a quarter of the villages had a local health facility. Both the proportion of health-facility deliveries and the proportion of children taken to a local health facility prior to death provide evidence of a very low attendance at health centres. Even in the group of children born in a health facility, nearly $10 \%$ had no birth weight recorded, and the apparent over-prescription of ineffective drugs (for example chloroquine), are both indicative of the poor quality of care provided in some health centres. It is likely that the overall low attendance at health facilities is in part a reflection of this poor quality of care, either due to poor outcomes among patients, or to little consideration shown to attendants by the health staff.

Other reasons for high IMRs include low maternal education, poverty and understaffing of health facilities, a quasi-permanent triad in the study area. In this study most of mothers had no formal education, a quarter was high multiparae and the ratios of health personnel to population were extremely low [12]. Socioeconomic status was measured using household assets but we found no association between the generated wealth index and risk of infant death. In the study area, over $80 \%$ of the population has farming as the major source of income and Banfora region is, relatively speaking, one of the less poor areas in this poor country $[11,12,32]$.

Alternative explanations for such high IMR might be selection or reporting bias. However, a random sample of eligible mothers was selected for data collection [15]. We also paid careful attention to the training and field supervisions of data collectors and also to the standardisation of questionnaires and their administration $[14,15]$. Furthermore, the involvement of "recruiters" from local communities in data collection improved the timeliness of information, as well as the acceptance and confidence granted to our study team. In this prospective cohort study, we made sure data collectors visited mothers and recorded all infant deaths, irrespective of whether the local "recruiter" had notified the case. The VA questionnaire was administered directly to the child's mother as long as she was available, and interviews were conducted in local languages to reduce misunderstanding. Infant deaths are important social events in the study area and it is very unlikely that a live child would be reported as having died.

\section{Probable causes of infant deaths by 6 months of age}

The most frequent probable causes of deaths identi fied during the first half of infancy were infections and preterm birth complications, consistent with published literature from Burkina Faso [33-35] and elsewhere [36]. Infections can be worsened by malnutrition $[27,37]$. The reported high proportions of acute respiratory tract infections and malaria in infant deaths from infectious causes are consistent with the epidemiological patterns of these two diseases in the study area [28,33-35,38]. These findings are also consistent with the observed higher infant death rate in the dry season during the first half of infancy and the lower rate of infant death in the postneonatal period for infants whose mothers were reported to sleep under a bednet. Previous studies in Burkina Faso have reported that mortality due to acute respiratory infections peaks during first half of infancy and during the dry season, and is higher in rural settings $[35,38]$.

\section{Risk factors for infant death}

Of the factors explored in this cohort, polygyny, maternal history of child death, twin births and poor anthropometric status at week-3 were associated with an increased mortality rate. 
Table 4 Association of maternal and infant baseline with infant death rate at different child age in univariable Cox regressions in a cohort of 866 live births in Banfora Health District (Burkina Faso)

\begin{tabular}{|c|c|c|c|c|c|c|c|c|c|c|c|c|}
\hline \multirow[t]{3}{*}{ Exposure variables } & \multicolumn{4}{|c|}{0 to 6 months ( $1^{\text {st }}$ half of infancy) } & \multicolumn{4}{|c|}{ 1-12 months (postneonatal period) } & \multicolumn{4}{|c|}{0 to 12 months (overall infancy) } \\
\hline & \multirow[t]{2}{*}{ PYO } & \multirow{2}{*}{$\begin{array}{l}\text { No of } \\
\text { deaths }\end{array}$} & \multirow[t]{2}{*}{$\mathrm{MRs}^{\mathrm{a}}$} & \multirow{2}{*}{$\frac{\mathrm{HR}^{\mathrm{b}}}{[95 \% \mathrm{Cl}]}$} & \multirow[t]{2}{*}{ PYO } & \multirow{2}{*}{$\begin{array}{l}\text { No of } \\
\text { deaths }\end{array}$} & \multirow[t]{2}{*}{$\mathrm{MRs}^{\mathrm{a}}$} & \multirow{2}{*}{$\frac{\mathrm{HR}^{\mathrm{b}}}{[95 \% \mathrm{Cl}]}$} & \multirow[t]{2}{*}{ PYO } & \multirow{2}{*}{$\begin{array}{l}\text { No of } \\
\text { deaths }\end{array}$} & \multirow[t]{2}{*}{$\mathrm{MRs}^{\mathrm{a}}$} & \multirow{2}{*}{$\begin{array}{l}\mathrm{HR}^{\mathbf{b}} \\
{[95 \% \mathrm{Cl}]}\end{array}$} \\
\hline & & & & & & & & & & & & \\
\hline \multicolumn{13}{|l|}{ Area of residence } \\
\hline - Banfora & 198.3 & 43 & 217 & $1.7[0.8-3.5]$ & 356.3 & 29 & 81 & $1.1[0.5-2.5]$ & 387.7 & 56 & 144 & $1.6[0.8-2.9]$ \\
\hline - Soubakenedougou & 102.1 & 13 & 127 & 1 & 183.9 & 13 & 70 & 1 & 200.0 & 18 & 90 & 1 \\
\hline - Sideradougou & 106.6 & 19 & 178 & $1.4[0.7-2.8]$ & 191.6 & 16 & 83 & $1.2[0.6-2.4]$ & 208.6 & 24 & 115 & $1.3[0.7-2.3]$ \\
\hline \multicolumn{13}{|c|}{ Distance to nearest health facility } \\
\hline - $\leq 5 \mathrm{~km}$ & 192.9 & 44 & 228 & $1.5[0.9-2.7]$ & 346.7 & 28 & 81 & $1.0[0.6-1.7]$ & 377.5 & 55 & 146 & 1.4 [0.9-2.2] \\
\hline - $>5 \mathrm{~km}$ & 214. & 31 & 145 & 1 & 385.2 & 30 & 79 & 1 & 418.8 & 43 & 103 & 1 \\
\hline \multicolumn{13}{|l|}{ Maternal age } \\
\hline - $<20$ & 61.9 & 12 & 193 & $1.6[0.5-5.2]$ & 111.8 & 9 & 80 & $3.1[0.6-15.0]$ & 121.6 & 17 & 140 & 1.9 [0.6-6.5] \\
\hline - 20-35 & 302.4 & 58 & 192 & 1 & 542.6 & 47 & 87 & 1 & 590.6 & 75 & 127 & 1 \\
\hline - $>35$ & 42.6 & 5 & 11 & $1.6[0.6-4.1$ & 77.4 & 2 & 26 & $3.3[1.0-11.2]$ & 84.1 & 6 & 71 & $1.7[0.7-4.4]$ \\
\hline \multicolumn{13}{|l|}{ Maternal parity } \\
\hline .0 & 63.8 & 15 & 235 & $1.4[0.6-3.2]$ & 115.0 & 10 & 87 & 1.0 [0.4-2.3] & 125.2 & 19 & 152 & $1.3[0.6-2.8]$ \\
\hline - 1 & 65.9 & 13 & 197 & $1.2[0.5-2.9]$ & 118.8 & 11 & 51 & 1.1. [0.4 2.9] & 129.2 & 17 & 131 & $1.1[0.5-2.6]$ \\
\hline - $2-4$ & 193.1 & 31 & 160 & $1.2[0.6-2.1$ & 346.3 & 29 & 58 & 1 & 376.9 & 43 & 114 & 1 \\
\hline - $5+$ & 84.0 & 16 & 190 & 1 & 151.8 & 8 & 26 & 0.6 [0.3-1.3] & 165.0 & 19 & 115 & 1.0 [0.6-1.7] \\
\hline \multicolumn{13}{|l|}{ History of child death ${ }^{c}$} \\
\hline - Yes & 201.1 & 40 & 199 & $1.4[0.8-2.3]$ & 359.6 & 35 & 97 & $1.8[0.8-4.2]$ & 391.5 & 54 & 138 & $1.5[1.0-2.3]$ \\
\hline - No & 142.0 & 20 & 141 & 1 & 257.3 & 13 & 50 & 1 & 279.5 & 25 & 89 & 1 \\
\hline \multicolumn{13}{|l|}{ Polygynous household } \\
\hline - Yes & 194.3 & 47 & 242 & $1.8[1.0-3.3]$ & 345.6 & 37 & 107 & $1.9[0.9-4.1]$ & 376.7 & 61 & 162 & $1.8[1.0-3.3]$ \\
\hline - No & 212.6 & 28 & 131 & 1 & 386.3 & 21 & 54 & 1 & 419.6 & 37 & 88 & 1 \\
\hline Maternal education & & & & & & & & & & & & \\
\hline - None & 326.8 & 61 & 187 & $1.5[0.7-3.3]$ & 586.5 & 49 & 83 & $3.8[0.5-27.0]$ & 638.4 & 78 & 122 & $2.0[0.9-4.3]$ \\
\hline - Literacy/primary school & 55.2 & 11 & 199 & $1.6[0.6-4.6] 1$ & 99.8 & 8 & 80 & $3.6[0.4-32.0]$ & 108.5 & 17 & 157 & $2.5[1.0-6.4]$ \\
\hline - Secondary school & 24.9 & 3 & 120 & 1 & 45.5 & 1 & 22 & 1 & 49.4 & 3 & 61 & 1 \\
\hline Socio-economic status $^{\mathbf{d}}$ & & & & & & & & & & & & \\
\hline - Q1 (most poor) & 86.6 & 13 & 150 & 1 & 157.4 & 8 & 51 & 1 & 171.1 & 17 & 99 & 1 \\
\hline - Q2 & 73.5 & 21 & 286 & $1.9[0.8-4.6]$ & 131.2 & 12 & 91 & $1.8[0.7-4.5]$ & 142.9 & 26 & 182 & $1.8[0.8-4.1]$ \\
\hline - Q3 & 83.8 & 16 & 191 & $1.3[0.6-2.7]$ & 150.1 & 13 & 87 & $1.7[0.7-4.2]$ & 163.5 & 21 & 128 & $1.3[0.7-2.4]$ \\
\hline - $\mathrm{Q} 4$ & 83.5 & 11 & 132 & $0.9[0.4-2.1]$ & 151.6 & 8 & 53 & $1.0[0.3-3.5]$ & 164.5 & 14 & 85 & $0.8[0.4-1.9]$ \\
\hline -Q5 (less poor) & 79.5 & 14 & 176 & $1.2[0.6-2.3]$ & 141.5 & 17 & 120 & $2.3[1.1-4.9]$ & 154.2 & 20 & 130 & $1.3[08-2.0]$ \\
\hline Mother sleeps under bednet & & & & & & & & & & & & \\
\hline - Yes & 156.7 & 25 & 159 & 1 & 284.1 & 16 & 56 & 1 & 308.7 & 32 & 103 & 1 \\
\hline - No & 250.2 & 50 & 200 & $1.2[0.6-2.5]$ & 447.8 & 42 & 94 & $1.6[1.0-2.8]$ & 487.6 & 66 & 135 & $1.3[0.7-2.2]$ \\
\hline Antenatal care visit & & & & & & & & & & & & \\
\hline .0 & 112.2 & 20 & 178 & $1.2[0.5-2.7]$ & 203.1 & 13 & 64 & $0.9[0.4-1.7]$ & 221.0 & 25 & 113 & $1.1[0.6-2.0]$ \\
\hline$\cdot 1-2$ & 218.2 & 44 & 201 & $1.4[0.7-2.7]$ & 390.5 & 35 & 89 & $1.2[0.7-2.1]$ & 425.1 & 58 & 136 & $1.3[0.8-2.2]$ \\
\hline$\cdot>2$ & 76.5 & 11 & 144 & 1 & 138.2 & 10 & 72 & 1 & 150.2 & 15 & 100 & 1 \\
\hline
\end{tabular}


Table 4 Association of maternal and infant baseline with infant death rate at different child age in univariable Cox regressions in a cohort of $\mathbf{8 6 6}$ live births in Banfora Health District (Burkina Faso) (Continued)

\begin{tabular}{|c|c|c|c|c|c|c|c|c|c|c|c|c|}
\hline \multicolumn{13}{|l|}{ Birth attendant } \\
\hline - Health personnel & 154.2 & 28 & 181 & 1 & 275.4 & 31 & 112 & 1 & 299.7 & 41 & 137 & 1 \\
\hline - TBA/family/other & 252.7 & 47 & 186 & $1.0[0.7-1.5]$ & 456.5 & 27 & 59 & $0.5[0.3-8]$ & 496.6 & 57 & 115 & $0.8[0.6-1.2]$ \\
\hline \multicolumn{13}{|l|}{ Season of delivery } \\
\hline - Dry season (Nov-Apr) & 189.1 & 40 & 211 & $1.3[0.9-2.0]$ & 339.7 & 26 & 76 & $0.9[0.6-1.3]$ & 369.6 & 50 & 135 & $1.2[0.8-1.7]$ \\
\hline - Rainy season (May-Oct) & 217.8 & 35 & 160 & 1 & 392.2 & 32 & 81 & 1 & 426.7 & 48 & 112 & 1 \\
\hline \multicolumn{13}{|l|}{ Sex of newborn } \\
\hline - Girl & 201.7 & 32 & 158 & 1 & 362.8 & 29 & 80 & 1 & 394.6 & 48 & 121 & 1 \\
\hline - Boy & 205.2 & 43 & 209 & $1.3[0.8-2.1]$ & 369.0 & 29 & 78 & $1.0[0.6-1.6]$ & 401.7 & 50 & 124 & $1.0[0.7-1.5]$ \\
\hline \multicolumn{13}{|l|}{ Twin births } \\
\hline - Yes & 13.3 & 18 & 1349 & $8.3[4.8-14.5]$ & 21.5 & 10 & 465 & $6.7[3.12 .7]$ & 24.0 & 21 & 876 & $7.7[4.6-12.8]$ \\
\hline - No & 393.6 & 57 & 145 & 1 & 710.4 & 48 & 67 & 1 & 772.3 & 77 & 100 & 1 \\
\hline \multicolumn{13}{|c|}{ Low anthropometric z-scores at week-3 ${ }^{\mathbf{e}}$} \\
\hline - Yes & 101.9 & 18 & 177 & $4.0[1.5-10.5]$ & 180.3 & 25 & 138 & $3.2[1.8-5.7]$ & 196.5 & 27 & 137 & $3.2[1.8-5.9]$ \\
\hline . No & 253.1 & 11 & 43 & 1 & 461.0 & 20 & 43 & 1 & 500.2 & 21 & 42 & 1 \\
\hline
\end{tabular}

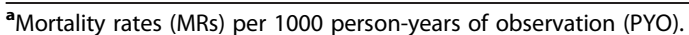

${ }^{b}$ All crude analyses adjusted for the cluster-design of the main EBF-study and estimates of HRs are with robust standard errors.

'Restricted only to multiparous mothers.

d See Table 1 for computation of the index of household assets.

${ }^{\mathbf{e}}$ Applicable only to those with weight or height measured at week-3 visit ( \pm 7 days, $N=723$ ).

Polygyny has previously been reported to be associated with increased risk of child death at several ages [39,40] although this is not a consistent finding [41]. We believe this variable could be a surrogate for poor socioeconomic status or an indicator of the women's status in our settings. Polygyny was common in Banfora and has in some studies, been associated with poor socioeconomic status and parental neglect $[11,40]$.

A maternal history of child death has been reported in several other studies to be associated with an increased risk of infant death including two studies from Burkina $[34,42]$. Our findings are consistent with those reports. It is likely that persistent harmful practices could contribute.

Twin births were at a very high risk of death in this cohort as found in previous studies in Burkina Faso where twins had over 4-times increased risk of infant death $[34,43,44]$. Our findings suggest that the death rate remains high for twins until 6 months of age. Multiple births were found in several studies from Africa to have an increased risk of death especially in the neonatal period $[16,45,46]$. Preterm birth and low birth weight, both frequently associated with multiple births, both increase the risk of early death.

Low anthropometric z-scores at 3 weeks of age were associated with a 3-times higher rate of infant death in the postneonatal period. Because of the number of children who did not have anthropometric data at week-3 and due to the potential interaction between birth weight and history of previous child death (which relates to maternal parity), we did not include this variable in the adjusted models for the period of the first half of infancy or entire infancy. Our data strengthen the existing knowledge on the association between malnutrition and high child mortality $[47,48]$.

A surprising finding at first sight is that of a higher death rate in the group of children living closer to a health facility. This was largely due to the high mortality rates observed in the 2 study clusters with the highest IMRs. Alternative explanations of this result in contrast to previous data from Burkina Faso [22,34], is either the difference in the cut-off point used (as shown) or it may relate to the already mentioned poor quality of care in facilities. The presence of a facility itself will not make any difference if villagers do attend it only in case of complications, if the centre is poorly equipped or if the health staff is not adequately trained.

Our study had some limitations amongst which, its low power to detect risk factors associated with a small increase in infant death rate (example household assets, parity, maternal education and number of ANC visits) and the high proportion of deaths with missing probable causes due both to initial study design and cultural context where detailed description of the circumstance of early child death by the mother was emotionally difficult. Another limitation was the variation in villages' population that may have resulted in lower probability of 
Table 5 Multivariable analyses of factors associated with infant death rate at different child age in a cohort of 866 live births in Banfora Health District (multivariable Cox regression models)

\begin{tabular}{|c|c|c|c|}
\hline \multirow[t]{4}{*}{ Exposures } & $1^{\text {st }}$ half infancy & Postneonatal period & Overall infancy \\
\hline & $\overline{\mathrm{HR}[95 \% \mathrm{Cl}]}$ & $\mathrm{HR}[95 \% \mathrm{Cl}]$ & $\mathrm{HR}[95 \% \mathrm{Cl}]$ \\
\hline & $n=727$ & $n=720$ & $\mathrm{n}=727$ \\
\hline & $\mathrm{N}=60$ deaths & $\mathrm{N}=45$ deaths & $\mathrm{N}=79$ deaths \\
\hline \multicolumn{4}{|l|}{ Distance to health facility } \\
\hline$\cdot \leq 5 \mathrm{~km}$ & $1.5[0.8-3.1]^{\mathbf{a}}$ & & $1.6[0.8-2.8]^{\mathbf{c}}$ \\
\hline$\cdot>5 \mathrm{~km}$ & 1 & & 1 \\
\hline \multicolumn{4}{|l|}{ History of child death } \\
\hline - Yes & $1.5[1.0-2.7]^{\mathbf{a}}$ & $1.6[1.0-2.6]^{\mathrm{c}}$ & \\
\hline - No & 1 & 1 & \\
\hline \multicolumn{4}{|l|}{ Polygynous household } \\
\hline - Yes & $2.4[1.3-4.3]^{\mathbf{a}}$ & $2.0[1.1-3.6]^{\mathbf{b}}$ & $2.4[1.4-4.0]^{\mathbf{c}}$ \\
\hline$\cdot$ No & 1 & 1 & 1 \\
\hline \multicolumn{4}{|l|}{ Mother sleeps under bednet } \\
\hline - Yes & & 1 & 1 \\
\hline$\cdot$ No & & $1.8[0.9-3.4]^{\mathbf{b}}$ & $1.3[0.8-2.1]^{c}$ \\
\hline \multicolumn{4}{|l|}{ Season of birth } \\
\hline - Dry season (Nov-Apr) & $1.4[0.8-2.4]^{\mathrm{a}}$ & & $1.4[0.9-2.1]^{c}$ \\
\hline - Rainy season (May-Oct) & 1 & & 1 \\
\hline \multicolumn{4}{|l|}{ Sex of newborn } \\
\hline . Girl & 1 & & 1 \\
\hline - Boy & $1.8[1.0-3.1]^{\mathbf{a}}$ & & $1.2[0.8-2.0]^{c}$ \\
\hline \multicolumn{4}{|c|}{ Low anthropometric $z$-scores at week-3 visit } \\
\hline - Yes & & $3.3[1.8-6.0]^{\mathbf{b}}$ & \\
\hline$\cdot$ No & & 1 & \\
\hline \multicolumn{4}{|l|}{ Twin births } \\
\hline - Yes & $10.6[5.4-20.8]^{\mathrm{a}}$ & & $8.4[4.6-15.3]^{\mathbf{c}}$ \\
\hline$\cdot$ No & 1 & & 1 \\
\hline
\end{tabular}

women from larger or high fertility villages of being recruited.

Nonetheless, our study is a rarity in Burkina Faso, being a recent prospective, community-based cohort study in a rural area. The use of a random sample of pregnant women for data collection reduced the selection bias to a minimum and we achieved a very high follow-up rate by one year. Another strength of this study was the follow-up of multiple births and their inclusion in the analyses.

\section{Conclusions}

This study showed a very high risk of infant death in a rural area of Burkina Faso. Twin births, poor anthropometric status at week-3, a maternal history of child death and polygyny were the factors associated with an increased risk of infant death. Preterm birth complications and infections were the major causes of death by 6 months. Attendance at health centres at delivery and during infancy illness was low. Further studies are needed to understand the relation of quality of care in health facilities and child survival in rural areas of Burkina Faso. With the observed IMRs in a predominantly rural country, Burkina Faso is unlikely to meet MDG-4 by 2015.

Achieving MDG-4 in this country will require a reduction of infant mortality in rural areas and any efficacious intervention should rely on a comprehensive approach that strengthens the existing health facilities, improves 
the training of health personnel and treatment of infections and also accounts for the perceived barriers to accessing quality care in health centres.

\section{Competing interests}

The authors declare no conflict of interest.

\section{Authors' contributions}

$A H D, N M, H S$ and $T T$ have designed the study. AHD conducted the study, performed data analyses and drafted the manuscript. GST contributed to data collection. SC contributed to data analyses. SC, NM, GST, HS and TT contributed to interpretation of the findings. All authors contributed to the writing of, and approved the final manuscript.

\section{Authors' information}

The PROMISE-EBF study group*

Steering Committee:

Thorkild Tylleskär, Philippe Van de Perre, Eva-Charlotte Ekström, Nicolas Meda, James K. Tumwine, Chipepo Kankasa, Debra Jackson.

Participating countries and investigators:

Norway: Thorkild Tylleskär, Ingunn MS Engebretsen, Lars Thore Fadnes, Eli Fjeld, Knut Fylkesnes, Jørn Klungsøyr, Anne Nordrehaug-Åstrøm, Øystein Evjen Olsen, Bjarne Robberstad, Halvor Sommerfelt

France: Philippe Van de Perre

Sweden: Eva-Charlotte Ekström, Barni Nor

Burkina Faso: Nicolas Meda, Abdoulaye Hama Diallo, Thomas W. Ouédraogo Jeremi Rouamba, Bernadette Traoré, Germain Traoré, Emmanuel Zabsonré Uganda: James K. Tumwine, Caleb Bwengye, Charles Karamagi, Victoria Nankabirwa, Jolly Nankunda, Grace Ndeezi, Margaret Wandera Zambia: Chipepo Kankasa, Mary Katepa-Bwalya, Chafye Siuluta, Seter Siziya South Africa: Debra Jackson, Mickey Chopra, Mark Colvin, Tanya Doherty, Ameena E Goga, Lungiswa Nkonki, David Sanders, Wesley Solomons, Wanga Zembe.

\section{Funding source}

The PROMISE-EBF study was funded by the European Commission Framework Programme-6 under the contract INCO-CT-2004-003660. The sponsor had no responsibility in the design, conduct, analysis, interpretation or publication of the data.

\section{Acknowledgments}

We are grateful to all mothers enrolled in the study for their participation and patience during interviews with a special thought for those who lost their child. We wish to acknowledge the enthusiasm of the local "recruiters" in the 24 villages of the Banfora Health District and the contribution of the five data collectors and their supervisors during the data collection.

\section{Author details}

'Centre MURAZ Research Institute, Ministry of Health/Burkina Faso, PO Box 390, Bobo-Dioulasso, Burkina Faso. ${ }^{2}$ Centre for International Health $(\mathrm{ClH})$, University of Bergen, PO Box 7804N-5020, Bergen, Norway. ${ }^{3}$ Division of Infectious Diseases Control, Norwegian Institute of Public Health, Oslo, Norway. ${ }^{4}$ Regional Nursing School of Public Health (ENSP/Bobo), Bobo-Dioulasso, Burkina Faso. ${ }^{5}$ London School of Hygiene and Tropical Medicine, Department of Infectious Disease Epidemiology (IDEU), London, UK.

Received: 2 February 2012 Accepted: 29 August 2012

Published: 5 September 2012

\section{References}

1. United Nations: The Millennium Development Goals Report 2009. In UN Reports. New York: United Nations Department of Economic and Social Affairs; 2009

2. Rajaratnam JK, Marcus JR, Flaxman AD, Wang H, Levin-Rector A, Dwyer L, Costa M, Lopez AD, Murray CJ: Neonatal, postneonatal, childhood, and under-5 mortality for 187 countries, 1970-2010: a systematic analysis of progress towards Millennium Development Goal 4. Lancet 2010, 375(9730):1988-2008.

3. UNICEF: The State of the World's Children 2011: Adolescence an age of opportunity. In UNICEF-Publications. New York: UNICEF; 2011:148.
4. Bhutta AZ, Chopra M, Axelson H, Berman P, Boerma JT, Bryce J, Bustreo F, Cavagnero E, Cometto G, Daelmans B: Countdown to 2015 decade report (2000-10): taking stock of maternal, newborn, and child survival. Lancet 2032, 2010:375.

5. Black RE, Cousens S, Johnson HL, Lawn JE, Rudan I, Bassani DG, Jha P, Campbell H, Walker CF, Cibulskis R, et al: Global, regional, and national causes of child mortality in 2008: a systematic analysis. Lancet 2010, 375(9730):1969-1987.

6. Lozano R, Wang H, Foreman KJ, Rajaratnam JK, Naghavi M, Marcus JR, DwyerLindgren L, Lofgren KT, Phillips D, Atkinson C, et al: Progress towards Millennium Development Goals 4 and 5 on maternal and child mortality: an updated systematic analysis. Lancet 2011, 378(9797):1139-1165.

7. You D, Wardlaw T, Salama P, Jones G: Levels and trends in under-5 mortality, 1990-2008. Lancet 2010, 375(9709):100-103.

8. United Nations Inter-Agency Group for Child Mortality Estimation (IAGCME): Levels and Trends in Child Mortality: Report 2010. In Levels and Trends in Child Mortality. New York: UN/WHO/UNICEF; 2010.

9. Bhutta ZA, Lassi ZS: Empowering communities for maternal and newborn health. Lancet 2010, 375(9721):1142-1144.

10. Byass $P$, Graham WJ: Grappling with uncertainties along the MDG trail. Lancet 2011, 378(9797):1119-1120.

11. INSD MEF/Burkina Faso: Recensement General de la Population et de I'Habitat, 2006 (General Population Census, 2006). In RGPH. Ouagadougou (Burkina Faso): MEF/INSD; 2009:586. Accessible at URL http://www.insd.bf.

12. INSD MEF/Burkina Faso: La Région des Cascades en chiffres (Statistics of the Cascades Region in 2010). In Annuaires Statistiques Régionales. Ouagadougou (Burkina Faso): MEF/INSD; 2010:96. Accessible at URL http:// www.insd.bf/.

13. Institut National de la Statistique et de la Démographie (INSD) et ICF Macro: Enquête démographique et de santé (EDS-IV) et à indicateurs multiples (MICS), Burkina Faso 2010: Rapport préliminaire (BF, DHS-2010 \& MICS2010). In DHS-2010. Edited by Measure DHS IMelB. Calverton: INSD/MEF, Burkina Faso; 2011. Accessible at URL http://www.insd.bf/.

14. Diallo AH, Meda N, Zabsonré E, Sommerfelt H, Cousens S, Tylleskar T: Perinatal mortality in rural Burkina Faso: a prospective community-based cohort study. BMC Pregnancy Childbirth 2010, 10(45):1-9.

15. Tylleskar T, Jackson D, Meda N, Engebretsen IM, Chopra M, Diallo AH, Doherty T, Ekstrom EC, Fadnes LT, Goga A, et al: Exclusive breastfeeding promotion by peer counsellors in sub-Saharan Africa (PROMISE-EBF): a cluster-randomised trial. Lancet 2011, 378(9789):420-427.

16. Diallo AH, Meda N, Ouedraogo WT, Cousens S, Tylleskar T: A prospective study on neonatal mortality and its predictors in a rural area in Burkina Faso: can MDG-4 be met by 2015? J Perinatol 2011, 31(10):656-663.

17. World Health Organization: Standard neonatal verbal autopsy questionnaire. Revised version. In WHO/JHU/SNL. Geneva (Switzerland): WHO Publications; 2003.

18. Winbo IG, Serenius FH, Dahlquist GG, Kallen BA: NICE, a new cause of death classification for stillbirths and neonatal deaths Neonatal and Intrauterine Death Classification according to Etiology. Int J Epidemiol 1998, 27(3):499-504.

19. Mosley WH, Chen LC: An analytical framework for the study of child survival in developing countries. 1984. Bull World Health Organ 2003, 81(2):140-145.

20. Ward AC: The role of causal criteria in causal inferences: Bradford Hill's "aspects of association". Epidemiol Perspect Innov 2009, 6:2.

21. Diallo DA, Cousens SN, Cuzin-Ouattara N, Nebie I, Ilboudo-Sanogo E, Esposito F: Child mortality in a West African population protected with insecticide-treated curtains for a period of up to 6 years. Bull World Health Organ 2004, 82(2):85-91.

22. Schoeps A, Gabrysch S, Niamba L, Sie A, Becher H: The effect of distance to health-care facilities on childhood mortality in rural Burkina Faso. Am J Epidemiol 2011, 173(5):492-498.

23. Diallo DA, Sutherland C, Nebie I, Konate AT, Ord R, llboudo-Sanogo E, Greenwood BM, Cousens SN: Children in Burkina Faso who are protected by insecticide-treated materials are able to clear drug-resistant parasites better than unprotected children. J Infect Dis 2007, 196(1): 138-144.

24. Diallo DA, Sutherland C, Nebie I, Konate AT, Ord R, Pota H, Roper C, Ilboudo-Sanogo E, Greenwood BM, Cousens SN: Sustained use of insecticide-treated curtains is not associated with greater circulation of drug-resistant malaria parasites, or with higher risk of treatment failure 
among children with uncomplicated malaria in Burkina Faso. Am J Trop Med Hyg 2007, 76(2):237-244.

25. Kouyate B, Some F, Jahn A, Coulibaly B, Eriksen J, Sauerborn R, Gustafsson L, Tomson G, Becher H, Mueller O: Process and effects of a community intervention on malaria in rural Burkina Faso: randomized controlled trial. Malar J 2008, 7:50.

26. Muller O, Becher $\mathrm{H}$, van Zweeden AB, Ye Y, Diallo DA, Konate AT, Gbangou A, Kouyate B, Garenne M: Effect of zinc supplementation on malaria and other causes of morbidity in west African children: randomised double blind placebo controlled trial. BMJ 2001, 322(7302):1567.

27. Muller O, Garenne M, Kouyate B, Becher H: The association between protein-energy malnutrition, malaria morbidity and all-cause mortality in West African children. Trop Med Int Health 2003, 8(6):507-511.

28. Muller O, Traore C, Becher H, Kouyate B: Malaria morbidity, treatmentseeking behaviour, and mortality in a cohort of young children in rural Burkina Faso. Trop Med Int Health 2003, 8(4):290-296.

29. Muller O, Traore C, Kouyate B, Ye Y, Frey C, Coulibaly B, Becher H: Effects of insecticide-treated bednets during early infancy in an African area of intense malaria transmission: a randomized controlled trial. Bull World Health Organ 2006, 84(2):120-126.

30. Hounton S, Chapman G, Menten J, De Brouwere V, Ensor T, Sombie I, Meda $\mathrm{N}$, Ronsmans C: Accessibility and utilisation of delivery care within a Skilled Care Initiative in rural Burkina Faso. Trop Med Int Health 2008, 13(Suppl 1):44-52.

31. Nikiema L, Kameli Y, Capon G, Sondo B, Martin-Prevel Y: Quality of antenatal care and obstetrical coverage in rural Burkina Faso. $J$ Health Popul Nutr 2010, 28(1):67-75.

32. INSD MEF/Burkina Faso: Analyse des résultats de l'enquête annuelle sur les conditions de vie des ménages en 2007 (Annual survey on households living conditions in 2007). In EA/QUIBB 2007. Ouagadougou (Burkina Faso): INSD, MEF/Burkina Faso; 2007.

33. Becher H, Kynast-Wolf G, Sie A, Ndugwa R, Ramroth H, Kouyate B, Muller O: Patterns of malaria: cause-specific and all-cause mortality in a malariaendemic area of west Africa. Am J Trop Med Hyg 2008, 78(1):106-113.

34. Becher H, Muller O, Jahn A, Gbangou A, Kynast-Wolf G, Kouyate B: Risk factors of infant and child mortality in rural Burkina Faso. Bull World Health Organ 2004, 82(4):265-273.

35. Hammer GP, Some F, Muller O, Kynast-Wolf G, Kouyate B, Becher H: Pattern of cause-specific childhood mortality in a malaria endemic area of Burkina Faso. Malar J 2006, 5:47.

36. Liu L, Johnson HL, Cousens S, Perin J, Scott S, Lawn JE, Rudan I, Campbell H, Cibulskis R, Li M: Global, regional, and national causes of child mortality: an updated systematic analysis for 2010 with time trends since 2000 . Lancet 2012, 379(9832):2151-2161.

37. Muller $\mathrm{O}$, Becher $\mathrm{H}$ : Malnutrition and childhood mortality in developing countries. Lancet 2006, 367(9527):1978.

38. Lang T, Lafaix C, Fassin D, Arnaut I, Salmon B, Baudon D, Ezekiel J: Acute respiratory infections: a longitudinal study of 151 children in BurkinaFaso. Int J Epidemiol 1986, 15(4):553-560.

39. Amey FK: Polygyny and child survival in West Africa. Soc Biol 2002, 49(1-2):74-89

40. Gyimah SO: Polygynous marital structure and child survivorship in subSaharan Africa: some empirical evidence from Ghana. Soc Sci Med 2009, 68(2):334-342

41. Ukwuani AF, Cornwell TG, Suchindran MC: Polygyny and child survival in Nigeria: age-dependant effects. J Popul Res 2002, 19(2):17.

42. Prazuck T, Tall F, Roisin AJ, Konfe S, Cot M, Lafaix C: Risk factors for preterm delivery in Burkina Faso (west Africa). Int J Epidemiol 1993, 22(3):489-494.

43. Hammer GP, Kouyate B, Ramroth H, Becher H: Risk factors for childhood mortality in sub-saharan africa.A comparison of data from a demographic and health survey and from a demographic surveillance system. Acta Trop 2006, 98(3):212-218.

44. Jahn A, Kynast-Wolf $\mathrm{G}$, Kouyate B, Becher $\mathrm{H}$ : Multiple pregnancy in rural Burkina Faso: frequency, survival, and use of health services. Acta Obstet Gynecol Scand 2006, 85(1):26-32.

45. Edmond KM, Quigley MA, Zandoh C, Danso S, Hurt C, Owusu Agyei S, Kirkwood BR: Aetiology of stillbirths and neonatal deaths in rural Ghana: implications for health programming in developing countries. Paediatr Perinat Epidemiol 2008, 22(5):430-437.

46. Lawn JE, Cousens S, Zupan J: 4 million neonatal deaths: when? Where? Why? Lancet 2005, 365(9462):891-900.
47. Bhutta ZA, Ahmed T, Black RE, Cousens S, Dewey K, Giugliani E, Haider BA, Kirkwood B, Morris SS, Sachdev HP, et al: What works? Interventions for maternal and child undernutrition and survival. Lancet 2008, 371 (9610):417-440.

48. Black RE, Morris SS, Bryce J: Where and why are 10 million children dying every year? Lancet 2003, 361(9376):2226-2234.

doi:10.1186/1471-2458-12-739

Cite this article as: Diallo et al:: The high burden of infant deaths in rural Burkina Faso: a prospective community-based cohort study. BMC Public Health 2012 12:739.

\section{Submit your next manuscript to BioMed Central and take full advantage of:}

- Convenient online submission

- Thorough peer review

- No space constraints or color figure charges

- Immediate publication on acceptance

- Inclusion in PubMed, CAS, Scopus and Google Scholar

- Research which is freely available for redistribution

Submit your manuscript at www.biomedcentral.com/submit
() Biomed Central 